\title{
Use of integrated imaging and serum biomarker profiles to identify subclinical dysfunction in pediatric cancer patients treated with anthracyclines
}

Olga H. Toro-Salazar ${ }^{1,7^{*}}$, Ji Hyun Lee ${ }^{1}$, Kia N. Zellars², Paige E. Perreault², Kathryn C. Mason², Zhu Wang ${ }^{1}$, Kan N. Hor $^{3}$, Eileen Gillan' ${ }^{1}$, Caroline J. Zeiss ${ }^{4}$, Daniel M. Gatti ${ }^{5}$, Brooke T. Davey ${ }^{1}$, Shelby Kutty ${ }^{6}$, Bruce T. Liang ${ }^{7}$ and Francis G. Spinale ${ }^{2}$

\begin{abstract}
Background: Anthracycline induced cardiomyopathy is a major cause of mortality and morbidity among pediatric cancer survivors. It has been postulated that oxidative stress induction and inflammation may play a role in the pathogenesis of this process. Accordingly, the present study performed an assessment of biomarker profiles and functional imaging parameters focused upon potential early determinants of anthracycline induced cardiomyopathy.

Methods: Patients (10-22 years) were prospectively enrolled between January 2013 and November 2014. Thirteen subjects completed the study and underwent serial cardiac magnetic resonance imaging and plasma biomarker profiling performed 24-48 $\mathrm{h}$ after the first anthracycline dose and at set dose intervals. In addition, we collected plasma samples from 62 healthy controls to examine normal plasma biomarker profiles.

Results: Left ventricular ejection fraction (LVEF) decreased from $64.3 \pm 6.2$ at the first visit to $57.5 \pm 3.3(p=0.004) 1$ year after chemotherapy. A decline in longitudinal strain magnitude occurred at lower cumulative doses. A differential inflammatory/matrix signature emerged in anthracycline induced cardiomyopathy patients compared to normal including increased interleukin-8 and MMP levels. With longer periods of anthracycline dosing, MMP-7, a marker of macrophage proteolytic activation, increased by $165 \pm 54 \%$ whereas interleukin-10 an anti-inflammatory marker decreased by $75 \pm 13 \%$ (both $p<0.05$ ). MMP7 correlated with time dependent changes in EF.

Conclusions: Asymptomatic pediatric patients exposed to anthracycline therapy develop abnormal strain parameters at lower cumulative doses when compared to changes in EF. A differential biomarker signature containing both inflammatory and matrix domains occur early in anthracycline treatment. Dynamic changes in these domains occur with increased anthracycline doses and progression to anthracycline induced cardiomyopathy. These findings provide potential prognostic and mechanistic insights into the natural history of anthracycline induced cardiomyopathy.
\end{abstract}

Trial registration number: NCT03211520 Date of Registration February 13, 2017, retrospectively registered.

Keywords: Anthracyclines, Cardiotoxicity, Myocardial strain, Global systolic function

\footnotetext{
* Correspondence: otoro@connecticutchildrens.org

${ }^{1}$ Connecticut Children's Medical Center, 282 Washington Street, Hartford, CT

06106, USA

${ }^{7}$ Pat and Jim Calhoun Cardiology Center, University of Connecticut Health

Center, Farmington, CT, USA

Full list of author information is available at the end of the article
} 


\section{Background}

Anthracycline induced cardiomyopathy (AIC), an all too common sequelae of cancer treatment, results in the development and progression of heart failure and death [1-8]. While the contributory mechanisms of AIC are multifactorial including changes in cellular oxidative stress and viability, [9-17] the structural underpinning is left ventricular (LV) remodeling and dysfunction. Past studies have provided evidence that AIC is associated with myocyte hypertrophy and structural remodeling of the myocardial extracellular matrix, whereby a loss of normal fibrillar collagen architecture is replaced by interstitial fibrosis [18-21]. A predominant pathway by which extracellular remodeling occurs is through changes in the proteolytic pathways, such as the matrix metalloproteinases (MMPs), and the local endogenous tissue inhibitors of MMPs (TIMPs) [22, 23]. Shifts in the steady-state expression of MMPs and TIMPs have been identified to occur with inflammation and cytokine release as well as with oxidative stress, [24, 25] both of which are operative in the context of AIC [18, 26-28]. However, temporal profiles of MMP/TIMPs as well as the relation to indices of inflammation have not been examined with AIC. The primary objective of this study was to examine MMP/TIMP and cytokine plasma levels in pediatric cancer patients undergoing anthracycline (AC) therapy and perform a comparative analysis with age matched reference control subjects.
Cardiac magnetic resonance (CMR), has an important role in the identification of cardiotoxicity and detection of early cardiac injury $[20,29]$. A $10 \%$ reduction in ejection fraction (EF) to an EF $<55 \%$ is used to define Cancer Therapeutics-Related Cardiac Dysfunction (CTRCD) $[29,30]$. Although early cardiac injury, without significant reduction in LV EF has been increasingly recognized, [20, 29, 31, 32] serial assessment of LV geometry, EF and myocardial strain and the relation to determinants of remodeling, such as MMP/TIMP profiles, has not been performed in patients undergoing anthracycline therapy. The guiding hypothesis of this study is that early changes in CMR parameters and MMP/ TIMP/cytokine profiles occur in patients at increased risk for AIC.

\section{Methods}

\section{Study population}

Twenty subjects aged 10-22 years, diagnosed with cancer that required AC therapy, were prospectively enrolled between January 2013 and November 2014 at a single center. Seven subjects withdrew. Thirteen of twenty subjects enrolled completed 47 visits. The study inclusion criteria and study flow are shown in Fig. 1. CMR and biomarker studies were performed at the first visit, (V1) 30-60 mg/m² cumulative anthracycline dose, and 24-48 $\mathrm{h}$ following set cumulative AC doses, at maximal dosing, and at 1 year after completion of $\mathrm{AC}$

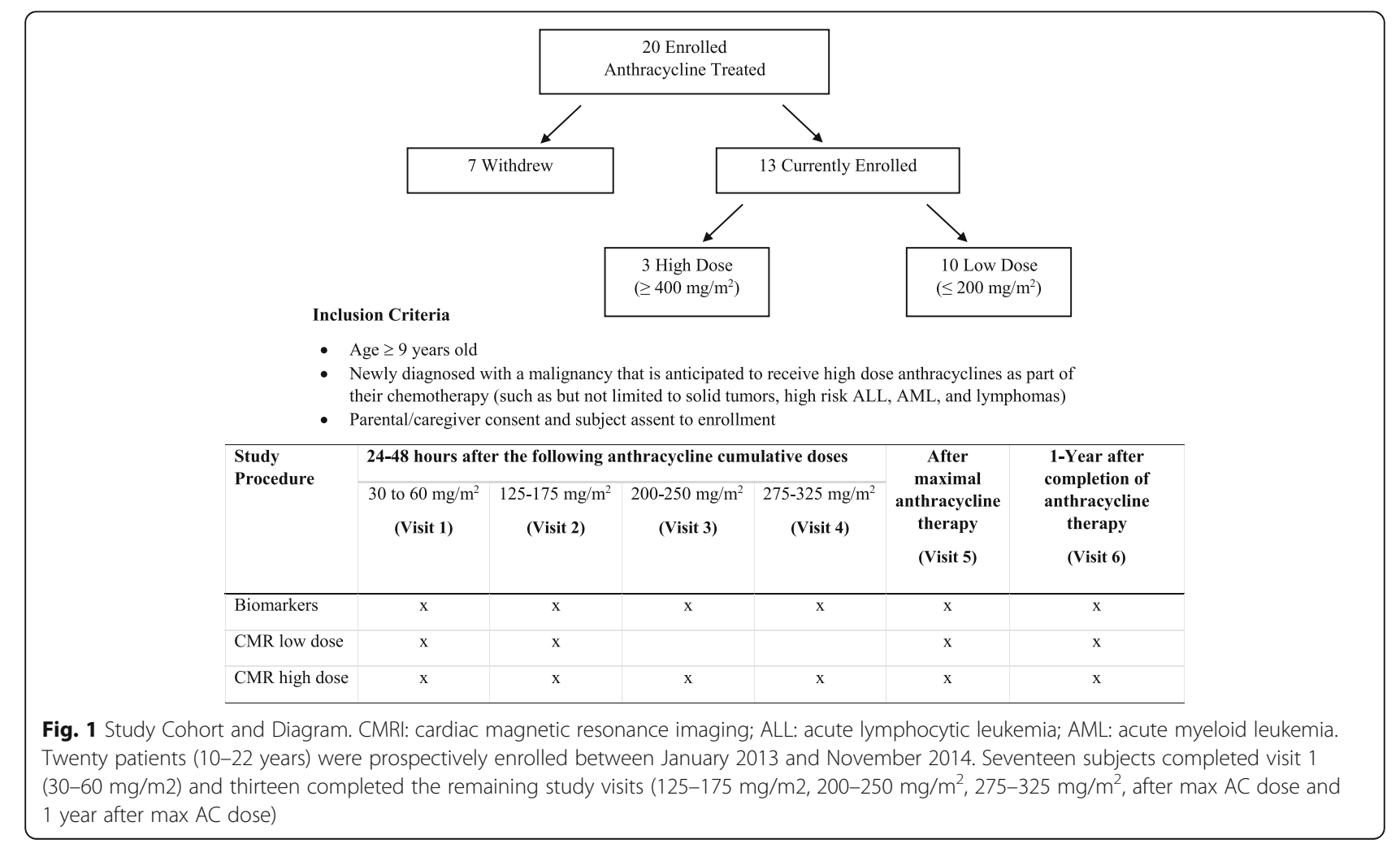


therapy (V6). Subjects were dichotomized based upon cumulative AC dose: low $\left(<240 \mathrm{mg} / \mathrm{m}^{2}\right)$ or high

$\left(>240 \mathrm{mg} / \mathrm{m}^{2}\right)$ as described previously [33]. The medical records of all completed subjects were reviewed to identify known risk factors associated with cardiotoxicity. Conversions to isotoxic equivalents of anthracyclines were performed to calculate total cumulative dose. Sixty-two healthy human subjects ( 30 males and 32 females, between 9 and 35 years of age) without cardiovascular disease were enrolled to obtain normative biomarker profiles. Recruitment was performed at Connecticut Children's Medical Center and Clinical Lab partners at the Hartford Hospital medical office building. Exclusion criteria included previous history of cardiac disease or cardiac surgery, history of chemotherapy, chronic disease or acute episode of illness (i.e. fever, upper respiratory symptoms, gastrointestinal illness, Lyme disease, mononucleosis). Demographic information for the control group is included in Table 1 and study design in Additional file 1: Figure S1.

\section{CMR techniques}

CMR techniques have been previously reported [20]. Subjects were imaged on a 1.5 Tesla (GE CV software version 16.0/M4, Milwaukee, WI) with the following protocol: (1) Standard multi-slice, multi-phase cine imaging using a steady state free precession acquisition technique (Fast Imaging Employing Steady-state Acquisition, FIESTA) in the 2 chamber, 4 chamber and contiguous short axis planes. (2) Tagged cine CMR acquired in the 4chamber and three short-axis planes (basal, mid-cavity, and apical) with an ECG-triggered segmented k-space fast gradient echo sequence with spatial modulation of magnetization in orthogonal planes. (3) Gadopentetate dimeglumine DTPA (Magnevist; Schering, Berlin, Germany) was administered intravenously at a dose of $0.1 \mathrm{mmol}$ per kilogram of body weight. (4) Late Gadolinium enhancement (LGE) was acquired 10-15 min after intravenous contrast for assessment of signal intensity changes in the 4-chamber and contiguous short axis planes. TI (time to inversion) was calculated to null the myocardium.

\section{Image analysis}

LV volumes, mass, and global function were measured via standard planimetry techniques with semi-automated computer software (QMASSversion 6.1.5, Medis Medical Imaging Systems, Leiden, the Netherlands) by an experienced reader (PI). Tagged images were analyzed with the HARmonic Phase (HARP, Diagnosoft, Palo Alto, California) technique [34] for calculation of peak average circumferential $(\varepsilon c c)$ and longitudinal strain $(\varepsilon ı)$. The CMR studies were de-identified and volumetric and HARP analysis of strain performed blindly by two experienced investigators (OTS, KNH).

Table 1 Demographics and other information of study population at first visit

\begin{tabular}{|c|c|c|c|c|c|}
\hline & $\begin{array}{l}\text { Study group }(n=13) \\
\text { Median }(25-75 \% \text { range) } \\
\text { or } n(\%)\end{array}$ & $\begin{array}{l}\text { Subjects who withdrew }(n=7) \\
\text { Median ( } 25-75 \% \text { range) } \\
\text { or } \mathrm{n}(\%)\end{array}$ & $p$ & $\begin{array}{l}\text { Control group }(n=62) \\
\text { Median }(25-75 \% \text { range }) \\
\text { or } n(\%)\end{array}$ & $p$ \\
\hline Age at diagnosis & $15.7(13.4-17.7)$ & $15(12-16.1)$ & .60 & $17(13-27)$ & .28 \\
\hline Female & $8(61.5)$ & $2(28.6)$ & .35 & $32(53.3)$ & .56 \\
\hline Total cumulative anthracyclines $\left(\mathrm{g} / \mathrm{m}^{2}\right)$ & $200(158-200)$ & NA & & NA & \\
\hline Vinca Alkaloids & $9(69.2)$ & NA & & NA & \\
\hline Previous bone marrow transplant & $0(0)$ & NA & & NA & \\
\hline Previous heart disease & $3(23.1)$ & NA & & NA & \\
\hline Height (cm) & $161(153-170.2)$ & NA & & NA & \\
\hline Weight (kg) & $54(40-84.8)$ & NA & & NA & \\
\hline BMI $\left(\mathrm{kg} / \mathrm{m}^{2}\right)$ & $20.6(17.9-22)$ & NA & & NA & \\
\hline Systolic pressure $(\mathrm{mmHg})$ & $108(106-117)$ & NA & & NA & \\
\hline Diastolic pressure $(\mathrm{mmHg})$ & $64(55-66)$ & NA & & NA & \\
\hline Number of transfusions $(n=11)$ & $10(0-49)$ & NA & & NA & \\
\hline Cancer Diagnosis & & & .03 & NA & \\
\hline ALL & $4(30.8)$ & $0(0)$ & & NA & \\
\hline Hodgkin's Lymphoma & $6(46.2)$ & $1(14.3)$ & & NA & \\
\hline AML & $1(7.7)$ & $2(28.6)$ & & NA & \\
\hline Osteosarcoma & $2(15.4)$ & $1(14.3)$ & & NA & \\
\hline Other & $0(0)$ & $3(42.9)$ & & NA & \\
\hline
\end{tabular}

$n$ number of subjects, SD standard deviation, BMI body mass index, $A L L$ acute lymphoblastic leukemia, $A M L$ acute myeloblastic leukemia All p-values are compared to the study group $(n=13)$ only 


\section{Methods for biomarkers}

Blood was collected from subjects, immediately centrifuged and the plasma layer removed. The separated plasma was divided into three equal aliquots and frozen at $-70{ }^{\circ} \mathrm{C}$. The following markers were measured: Matrix/Fibrosis pathway: Plasma levels of MMPs (all soluble MMP types) and TIMPs (all 4 TIMPs); Inflammatory domain: cytokines (TNF $\alpha$, interleukins, interferon gamma (IFNG), TGF $\beta 2$, TGF $\beta \mathrm{II})$ ), cytokine receptors (sTNF RI, sTNF RII, sSt2, sgp130, siL1RII/sCD121b, siL-2R $/$ CD25, siL-4R, siL-6R, Endoglin); Signaling pathway: growth factors (GDP-15, GCSF, VEGF, sVEGFR2 TGF $\beta 1$, IGF-1; The specific antisera and sensitivity for this approach is provided in Additional file 2: Table S1. All measurements were performed in duplicate using an internally validated and calibrated multiplex suspension array (two-laser flow cytometric detection system; Bio-Plex 200, BioRad Laboratories). The sensitivity for all of the assays was in the $\mathrm{pg} / \mathrm{mL}$ range, with intra-assay coefficient of variations less than $15 \%$.

\section{Statistical analysis}

Data are expressed as numbers with percentages and median values with ranges $(25 \%-75 \%)$, as appropriate. The Wilcoxon rank sum test was conducted to examine differences between study group and control group. Student's t-tests were used to examine differences between groups: high dose vs. low dose, and the first visit values compared to maximal dose and 1 year after chemotherapy, and to compare biomarker concentrations between subjects and controls. Spearman correlation analysis was conducted to assess the relationship between continuous variables. Non-parametric test for trend on MRI parameters across all visits was conducted and $p$-values are presented in Table 2. All tests were two-tailed, and $p<$ 0.05 was considered to indicate a statistically significant difference. Stata 14.2 (StataCorp, Texas USA) software was used for statistical analysis. To evaluate associations of biomarkers and time dependent changes in EF from V1 to V6, we utilized multilevel modeling for repeated measures ( $\mathrm{R}$ program $\mathrm{v}$ 3.4.0, $\mathrm{R}$ Foundation for Statistical Computing, Vienna, Austria). In the multilevel modeling for each biomarker, an overall linear change function is fitted to the whole sample and the slope and intercept are allowed to vary across individuals, i.e. defined as random coefficients. We report fixed regression coefficients that represent the associations between biomarkers and time dependent changes in EF from V1 to V6 averaged across subjects. Given the small sample size, we did not adjust p-values for multiple comparisons.

\section{Results}

The clinical and demographic characteristics for thirteen of twenty subjects who completed all visits is shown in Table 1 . Changes in imaging parameters $24-48 \mathrm{~h}$ after $\mathrm{AC}$ dose at all visits in high and low dose subjects are shown in Table 2. All subjects in the low dose group had diagnosis of leukemia or lymphoma with AC doses of $175.2 \pm 21.4$ compared to $447.3 \pm 4.6(p<.0001)$ in the high dose group (solid tumor diagnosis).

Table 2 LV Parameter trends (medians) by Cardiac Magnetic Resonance Imaging

\begin{tabular}{|c|c|c|c|c|c|c|c|c|c|c|c|c|}
\hline \multirow{2}{*}{$\begin{array}{l}\text { Cumulative AC Dose } \\
\left(\mathrm{mg} / \mathrm{m}^{2}\right)\end{array}$} & \multicolumn{7}{|c|}{ High dose group $(n=3)$} & \multicolumn{5}{|c|}{ Low dose group $(n=10)$} \\
\hline & $30-60$ & $125-175$ & $200-250$ & $275-325$ & After Max & 1 Year After & $p$ & $30-60$ & $125-175$ & After Max & 1 Year After & $\mathrm{p}$ \\
\hline LV EF (\%) & 66.8 & 61.2 & 58.7 & 57.6 & 55.8 & 55.3 & .005 & 62.6 & 60.8 & 60.4 & 57.9 & .11 \\
\hline LV EF z score & 0.57 & -0.62 & -1.1 & -1.4 & -1.7 & -1.9 & .005 & -0.3 & -0.6 & -0.8 & -1.3 & .11 \\
\hline LV EVDI (ml/m²) & 96.6 & 85.3 & 100.6 & 97.1 & 74.8 & 94.1 & .22 & 75.6 & 78.3 & 73.9 & 78.3 & .56 \\
\hline LV ESVI $\left(\mathrm{ml} / \mathrm{m}^{2}\right)$ & 23.5 & 33.2 & 40.3 & 41.1 & 31.8 & 41.5 & .30 & 29.3 & 30.7 & 29.9 & 33.0 & .58 \\
\hline LV SV (ml) & 132.3 & 88.5 & 87 & 85.6 & 77.5 & 99.2 & .35 & 73.4 & 67.5 & 73.9 & 67.6 & .93 \\
\hline LV Mass $\left(\mathrm{g} / \mathrm{m}^{2}\right)$ & 133 & 107.1 & 135 & 128 & 122 & 135.8 & .62 & 88.9 & 79.0 & 83 & 87.0 & .87 \\
\hline LV Mass z score & 0.4 & 0.7 & 0.2 & 0.5 & 0.3 & 0.6 & .42 & 0.6 & 0 & -0.2 & -0.2 & .03 \\
\hline LV Mass Volume (g/ml) & 0.7 & 0.8 & 0.8 & 0.8 & 0.9 & 0.8 & .26 & 0.8 & 0.8 & 0.7 & 0.7 & .19 \\
\hline LV Mass Volume z score & -1.0 & 0.5 & -0.3 & -0.5 & 0.9 & -0.4 & .54 & 0.5 & 0.7 & 0.3 & 0.2 & .28 \\
\hline ESFS $\left(\mathrm{g} / \mathrm{cm}^{2}\right)$ & 99 & 89.5 & 115 & 115 & 114 & 122 & .02 & 109 & 107.5 & 99 & 104 & .97 \\
\hline ESFS z score & 2.2 & 1.4 & 3.67 & 3.63 & 3.45 & 4.18 & .02 & 3.3 & 3.1 & 2.3 & 2.8 & .83 \\
\hline عс૮ (\%) & -22.5 & -20.3 & -19.1 & -18.1 & -16.3 & -18.9 & .02 & -21.1 & -19.0 & -19.3 & -19.9 & .45 \\
\hline દા (\%) & -19.1 & -19.3 & -16.2 & -15.8 & -14.7 & -17.4 & .02 & -18.0 & -16.0 & -15.5 & -16.4 & .56 \\
\hline
\end{tabular}

$L V$ left ventricular, CMR cardiac magnetic resonance imaging, $n$ number of subjects, $A C$ anthracycline, $E F$ ejection fraction, $E D V I$ end diastolic volume index, ESVI end systolic volume index, SV stroke volume, ESFS end systolic fiber stress; $\varepsilon c c$ peak global circumferential strain magnitude; $\varepsilon$ ll: Peak global longitudinal strain magnitude. All patients in the low dose group had diagnosis of leukemia or lymphoma with Anthracycline cumulative doses of $175.2 \pm 21.4$ compared to $447.3 \pm$ $4.6(p<.0001)$ in the high dose group (solid tumor diagnosis)

Bold numbers indicate statistically significant cardiac magnetic resonance imaging parameters 


\section{Imaging parameters}

Using CMR we compared the effect of AC therapy on LVEF $24-48 \mathrm{~h}$ following $30-60 \mathrm{mg} / \mathrm{m}^{2}$ of anthracyclines (first visit), after maximal therapy and 1 year after maximal therapy. The LVEF decreased from $64.7 \pm 6.1$ ( $\mathrm{Z}$ score: $0.1 \pm 1.3$ ) after the initial dose (V1) to $59.0 \pm 7.0$ ( $\mathrm{Z}$ score: $-1.1 \pm 1.5$ ), $p=0.04$ ( $\mathrm{Z}$ score $p=0.05$ ) at the end of maximal therapy. The mean decrease in EF was statistically significant when we compared LVEF between the first visit and 1 year after maximal therapy.

$(6.76 \pm 6.5$, Z score: $1.4 \pm 1.4, p=0.004 ; p=0.005$, respectively). Seven subjects demonstrated greater than $10 \%$ absolute unit reduction in EF from initial visit to maximal therapy. Three $(23.1 \%)$ of these subjects met criteria for CTRCD (cancer therapeutic related cardiac dysfunction) with $>10 \%$ reduction to an $\mathrm{EF}<55 \%$ at maximal therapy. Two of three subjects had a persistent reduction in EF 1 year after chemotherapy.

To better characterize early cardiotoxic effects of AC in the heart we then determined regional myocardial function by measuring average $\varepsilon \mathrm{cc}$ and $\varepsilon \mathrm{ul}$. Medians of LV parameters including strain values are included in Table 2 for all time visits.

\section{Regional myocardial function (strain)}

Complex fiber architecture in the heart results in complex patterns of deformation and changes in shape that are produced upon muscle contraction or relaxation. Each element of strain is simply a measurement of the fractional or the percent change of length in a specific direction where $L_{o}$ is the original fiber length before tag deformation and $\mathrm{L}$ is the current length (Strain $=\mathrm{L}-\mathrm{L}_{\mathrm{o}} /$ $\left.\mathrm{L}_{\mathrm{o}}\right)$. In a segment, radial strain $\left(\varepsilon_{R R}\right)$ describes myocardial thickening, which is in the radial direction towards the center of the ventricle. $\left(\varepsilon_{R R}\right)$ has high variability due to the impact of circumferential and longitudinal strain and thus has not been routinely used (Fig. 2a). Circumferential strain $(\varepsilon c c)$ of the same segment describes circumferential shortening, which is a direction tangential to the epicardial surface (Fig. 2b). The third strain component in a segment is longitudinal strain $(\varepsilon \|)$, which represents base-to-apical shortening along the ventricular long axis (Fig. 2c) [35]. The depreciation of the strain magnitude, or percent change, indicates the weakening of the myocardial in a segment. The average of segmental strain measurements over the ventricle is a measure of global strain. Global longitudinal strain $(\varepsilon \| 1)$, is currently considered the optimal parameter of deformation for the early detection of subclinical dysfunction in CTRCD [30]. For longitudinal and circumferential strain, a less negative value constitutes a reduction in strain magnitude (Fig. 2b and c). An absolute reduction in strain to $>-17 \%$ and /or a relative percentage decrease of $>15 \%$ compared with baseline is likely to be of

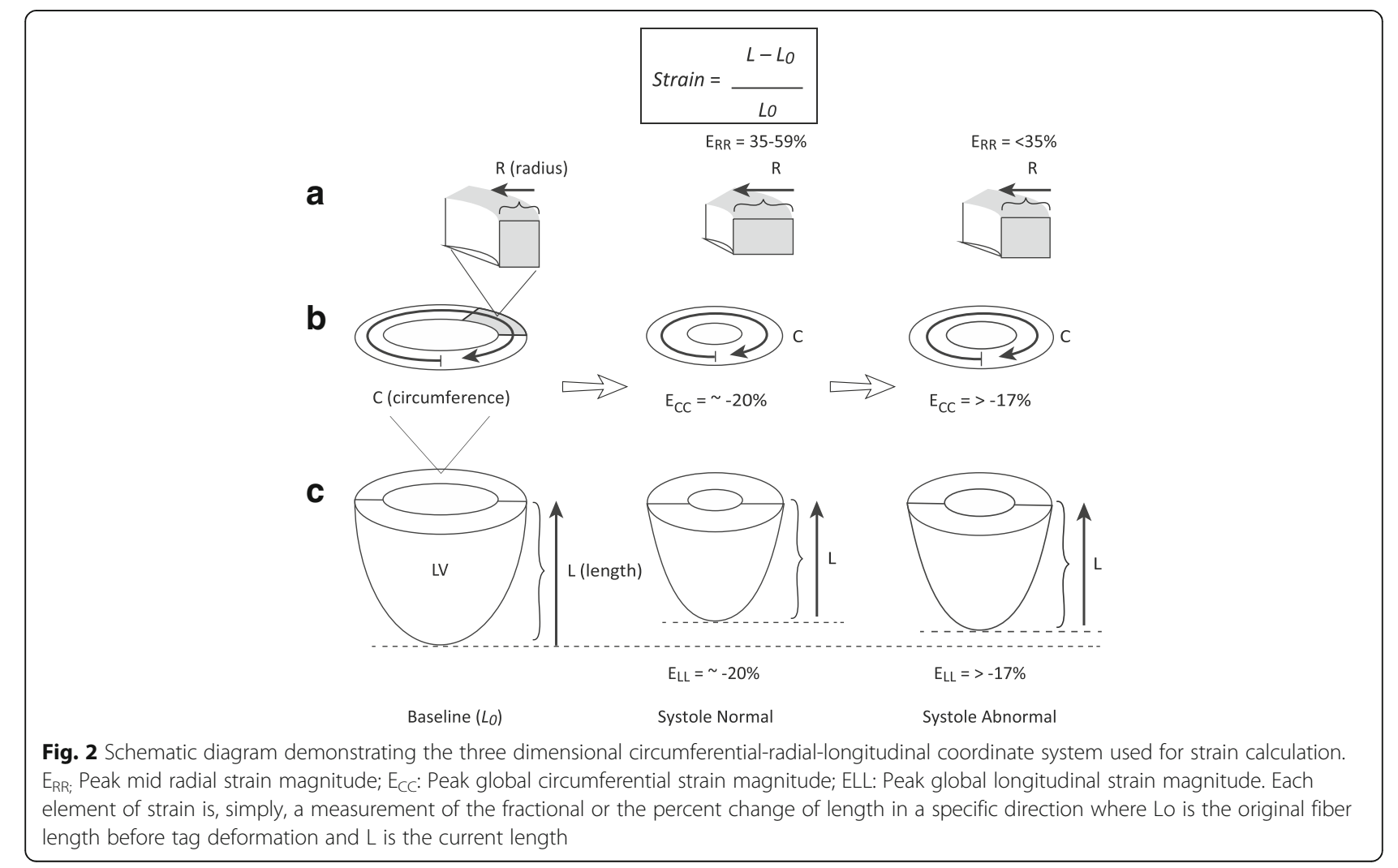


clinical significance. LV parameters including strain are included in Table 3 for all time visits.

\section{High dose group (mean AC cumulative dose $447.3 \pm$ $\left.4.6 \mathrm{mg} / \mathrm{m}^{2}\right) \mathrm{n}=3$}

There was a decrease in $\varepsilon \mathrm{cc}$ magnitude from -22.2 \pm 0.7 after $30-60 \mathrm{mg} / \mathrm{m}^{2}$ cumulative AC dose to $17.1 \pm 1.6(p=0.02)$ at maximal dose and a clinically significant decrease in $\varepsilon$ Il magnitude from-19.5 \pm 0.9 to $-15.8 \pm 2.8 \quad(p=.20)$. A clinically significant decline in $\varepsilon$ Il magnitude $(-17.2 \pm 1.9, p=0.25)$ occurred at lower cumulative doses $\left(200-250 \mathrm{mg} / \mathrm{m}^{2}\right)$ followed by a decline in $\varepsilon c c$ magnitude $(-17.8 \pm 2.6, p=0.07)$ at $275-325 \mathrm{mg} / \mathrm{m}^{2}$ and $\mathrm{EF}<55 \%$ at doses $>375 \mathrm{mg} /$ $\mathrm{m}^{2}$ (Table 2).

\section{Low dose group (mean AC cumulative dose $175.2 \pm$} $\left.21.4 \mathrm{mg} / \mathrm{m}^{2}\right) n=10$

There was a decrease in $\varepsilon$ Il magnitude from $-17.1 \pm 2.6$ to $-15.1 \pm 4.9$ at maximal therapy $(p=0.44)$ and no significant change in $\varepsilon \mathrm{Cc}$ magnitude from $-20.7 \pm 1.0$ at $\mathrm{V} 1$ to $-20.3 \pm 3.1$ at maximal therapy $(p=0.77)$.

\section{Biomarker analysis}

\section{The extracellular matrix (ECM) biomarker profiles}

The matrix metalloproteinases (MMPs) play a key role during cardiac remodeling [36]. Cardiac matrix alterations induced by anthracyclines [19] and strong transcriptional activation for several specific MMPs in anthracycline-induced cardiac remodeling has been demonstrated in several animal models $[21,37,38]$. We demonstrate an increase in MMP-2, MMP-7 and MMP9, and detectable levels of TIMP-3 and TIMP-4 in the anthracycline group $(p<0.05)$ (Fig. 3).

Table 3 Multilevel linear regression (biomarkers to changes in LV Ejection Fraction from V1 to V6)

\begin{tabular}{llllll}
\hline & Coef. & SE & DF & $\mathrm{t}$ & $\mathrm{p}$ \\
\hline ECc $(\%)$ & -1.5540 & 0.3924 & 35 & -3.9605 & $<.001$ \\
ESV $(\mathrm{ml})$ & -0.2496 & 0.0446 & 43 & -5.5980 & $<.001$ \\
ESFS $\left(\mathrm{g} / \mathrm{cm}^{2}\right)$ & -0.1584 & 0.0451 & 43 & -3.5114 & .0011 \\
MMP7 $(\mathrm{pg} / \mathrm{ml})$ & -0.0014 & 0.0006 & 43 & -2.4592 & .018 \\
sIL 4R $(\mathrm{pg} / \mathrm{ml})$ & 0.0034 & 0.0014 & 44 & 2.4405 & .0188 \\
sRage $(\mathrm{pg} / \mathrm{ml})$ & -0.0502 & 0.0216 & 44 & -2.3234 & .0248 \\
sTNFRI $(\mathrm{pg} / \mathrm{ml})$ & -0.0032 & 0.0015 & 44 & -2.1340 & .0385 \\
sTNFRII $(\mathrm{pg} / \mathrm{ml})$ & -0.0008 & 0.0003 & 44 & -2.4872 & .0167 \\
sVEGFR3 $(\mathrm{pg} / \mathrm{ml})$ & -0.0058 & 0.0022 & 44 & -2.6162 & .0121 \\
\hline
\end{tabular}

V1: first visit; V6: 1 year after maximal anthracycline therapy; $\varepsilon c c:$ Peak global longitudinal strain magnitude; ESV: End systolic volume; ESFS: End systolic fiber stress; MMP: Metalloproteinase; sILR: soluble interleukin receptor; sRage: receptor for advanced glycation end products; sTNFR: soluble receptor for TNF; SVEGFR: receptors for vascular endothelial growth factor

\section{Inflammation related biomarker profiles}

Cytokines are a family of bioactive signaling molecules that regulate the inflammatory response and have been recently identified as mediators in the development and progression of heart failure [39, 40]. These inflammatory mediators are now known to be expressed by all nucleated cell types residing in the myocardium, including the cardiac myocyte [41]. We used a multiplex array panel to quantify signatures from the inflammatory domain (cytokines, cytokine receptors) and signaling pathways. Statistically significant elevation in IL-8, IL-1 and IL-2 receptors (sIL1RII, sIL-2Ra) and soluble glycoprotein (sgp) 130, were observed in subjects $24-48 \mathrm{~h}$ after $30-60 \mathrm{mg} /$ $\mathrm{m}^{2}$ of AC therapy when compared to controls (Figs. 3 and 4). Similarly, there was a statistically significant early down-regulation of soluble IL-4 receptor (siL4R), the vascular endothelial growth factor (VEGF), and receptor for advanced glycation end products (sRage) (Fig. 4).

With longer periods of AC dosing, MMP-7, a marker of macrophage proteolytic activation, increased by $165+54 \%$ whereas interleukin-10 (IL-10) an anti-inflammatory marker fell by $75+13 \%$ (both $p<0.05$ ) (Fig. 5).

\section{Relation of LV dysfunction and biomarker profiles}

Having demonstrated an early $\left(30-60 \mathrm{mg} / \mathrm{m}^{2}\right)$ differential inflammatory signature and ECM biomarker profile in AIC patients, we then correlated them with regional and global parameters of myocardial function. Elevations in IL-8 at the first visit correlated with lower $\varepsilon \mathrm{CC}$ after maximal therapy $(r=-0.61, p=.04)$ and 1 year after chemotherapy $(r=-0.73, p=0.008)$. Low IL-10 at first visit was associated with a low $\varepsilon$ ll 1 year after chemotherapy $(r=-0.82, p=0.09)$ and $>10 \%$ decrease in EF from V1 to V6.

Early elevation in MMP7 levels $(30-60 \mathrm{mg} / \mathrm{m} 2)$ correlated with a $>10 \%$ decrease in EF from V1 to V6. (Table 3 and Additional file 2: Table S2). Early down regulation in several soluble receptors, including, siL4R, sRage, sTNFR1, sTNFRII and sVEGFR3 correlated with time dependent changes in EF from V1 to V6.

\section{Discussion}

This pilot study is a breakthrough in the use of serial combined functional imaging-serum biomarker profiling in a cohort of subjects undergoing AC chemotherapy. Decrease in CMR-derived $\varepsilon \mathrm{cc}$ and $\varepsilon \mathrm{ll}$, and increase and serologic biomarkers of matrix/fibrosis pathways, inflammatory domain cytokines, cytokine receptors and signaling pathways occur early in the course of anthracycline therapy. With higher AC cumulative doses, MMP-7, a marker of macrophage proteolytic activation increases, whereas there is a decrease in IL-10 an anti- 




inflammatory marker. Moreover, we demonstrate a subgroup of these biomarkers are associated with changes in EF from $\mathrm{V} 1$ (30-60 mg/m ${ }^{2} \mathrm{AC}$ dose) to V6 (1 year after chemotherapy). This biomarker signature may provide insights into the pathogenic mechanisms underlying cardiac remodeling and the transition to chronic delayed cardiotoxicity.

Early reduction in myocardial strain or strain rate magnitude using echocardiography has been shown to predict subsequent cardiotoxicity [30, 42, 43]. A relative percentage reduction of global longitudinal strain (GLS) of $>15 \%$ from baseline appears to be meaningful, and is likely to be abnormal [44]. Similarly, CMR-based spatial modulation of magnetization has shown a decline of mid-wall circumferential strain at 1 month of AC therapy, which remained reduced at 6 months [31]. This is the first study to demonstrate that changes in longitudinal and circumferential strain magnitude by CMR occur before changes in LVEF with increasing doses of anthracyclines. Furthermore, early measurement of regional deformation parameters $\left(30-60 \mathrm{mg} / \mathrm{m}^{2}\right)$ correlate with a decrease in $\mathrm{EF}>10 \%$ from $\mathrm{V} 1$ to $\mathrm{V} 6$.

Infiltration of the myocardium in acute and chronic leukemia has been reported previously [45]. Lower strain values at the first visit $\left(30-60 \mathrm{mg} / \mathrm{m}^{2}\right)$ were noted in patients with leukemia and lymphoma, when compared to those with solid tumors. AC doses were significantly lower in this group $(175.2 \pm 21.4$ compared to $447.3 \pm$ $4.6<.0001)$. Early decrease in myocardial deformation parameters in these patients is suggestive of baseline involvement of the myocardium related to their cancer diagnosis. Of significance, leukemia and lymphoma patients with the lowest strain values at first visit had the lowest EF after completion of AC therapy.

\section{Inflammation and relevance for biomarker profiling} Inflammatory mediators play an important role in LV remodeling. Major steps in this process include myocyte hypertrophy, [46] alterations in fetal gene expression, [47] progressive myocyte loss through apoptosis [48] and alterations in the extracellular matrix leading to microscopic fibrosis [17]. These inflammatory mediators are known to be expressed by all nucleated cell types residing in the myocardium [40]. Several studies have shown raised levels of inflammatory cytokines, such as tumor necrosis factor (TNF), interleukins from the IL-1 and IL- 6 families in plasma, and circulating leukocytes in heart failure patients [49]. Pro-inflammatory cytokines including TNF, IL-1 $\beta$, and IL-6 are upregulated with decreased heart function, and are activated earlier in heart failure than the classic neurohormones [50]. We demonstrated an early increase in IL- 8 and a decrease in the 
a

\begin{tabular}{|c|c|c|}
\hline & $\begin{array}{c}\text { Referent Normal } \\
\mathbf{n}=63\end{array}$ & $\begin{array}{c}\text { Visit 1 } \\
\mathbf{n}=\mathbf{1 7}\end{array}$ \\
\hline sCD30 $(\mathrm{pg} / \mathrm{mL})$ & $79.8 \pm 13.9$ & $70.4 \pm 12.4$ \\
\hline SEGRF $(\mathrm{pg} / \mathrm{mL})$ & $50757.9 \pm 1122.1$ & $51404.2 \pm 4066.2$ \\
\hline sIL-1RI $(\mathrm{pg} / \mathrm{mL})$ & $143.6 \pm 4.4$ & $141.3 \pm 14.6$ \\
\hline sIL-6R $(\mathrm{pg} / \mathrm{mL})$ & $19940.1 \pm 736.1$ & $22954.3 \pm 1838.9$ \\
\hline sTNFRI $(\mathrm{pg} / \mathrm{mL})$ & $1462.5 \pm 118.1$ & $1526.5 \pm 257.4$ \\
\hline sTNFRII $(\mathrm{pg} / \mathrm{mL})$ & $5623.3 \pm 271.2$ & $6983.8 \pm 1148.5$ \\
\hline sVEGFRI $(\mathrm{pg} / \mathrm{mL})$ & $1148.9 \pm 256.8$ & $1505.7 \pm 314.4$ \\
\hline sVEGFR2 $(\mathrm{pg} / \mathrm{mL})$ & $12697.4 \pm 1003.9$ & $11757.7 \pm 1156.6$ \\
\hline
\end{tabular}

b

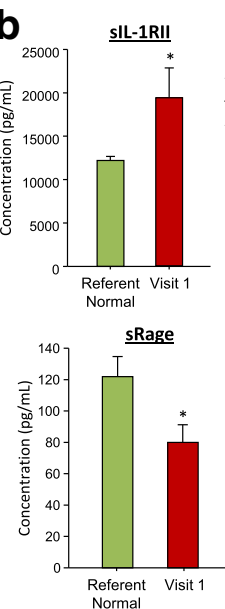

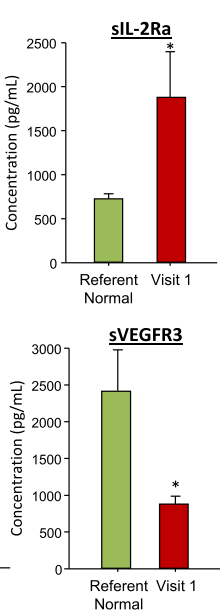
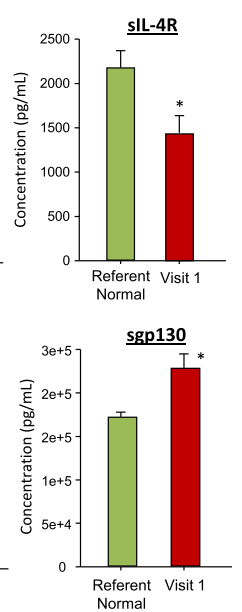

Fig. 4 Plasma profiling for specific determinants of inflammation and signaling. A number of inflammatory signaling pathways were profiled in plasma samples taken from age matched referent normal subjects and the initial visit following AC treatment- identified as Visit 1. While robust signals for the soluble IL, TNF and VEGF receptors were detected in both referent normal and Visit 1 samples many soluble receptor analytes were similar between groups and summarized in Table A. On the other hand, specific soluble receptors/pathways were significantly different from referent control values and are shown in Figure 2-2B. These included the soluble receptors for IL-1, -2 , and -4 . A relative reduction in sRage and sVEGFR3 occurred in Visit 1 samples with an increase in Sgp130. ( ${ }^{*} p<0.05$ vs Visit 1 values). Normal: referent normal; MMP-2: Matrix metallopeptidase 2; MMP-7: Matrix metallopeptidase 7; MMP-9: Matrix metallopeptidase 9; IL-8: Interleukin 8; sVEGFR3: Fms-related tyrosine kinase 4; sgp130: Interleukin 6 signal transducer; sIL-1RII: Interleukin 1 receptor, type II; slL-2Ra: Interleukin 2 receptor, alpha; sIL-4R: Interleukin 4 receptor

IL-8/IL-10 ratio in children with AIC, indicating proinflammatory activity. Similar findings have been reported in patients with heart failure [51] and in pediatric patients undergoing open heart surgery [52]. While soluble ligands circulate at low levels, their corresponding receptors are frequently detected at high levels in plasma, suggesting these receptors have potential as reliable biomarkers. We observed increased levels of soluble

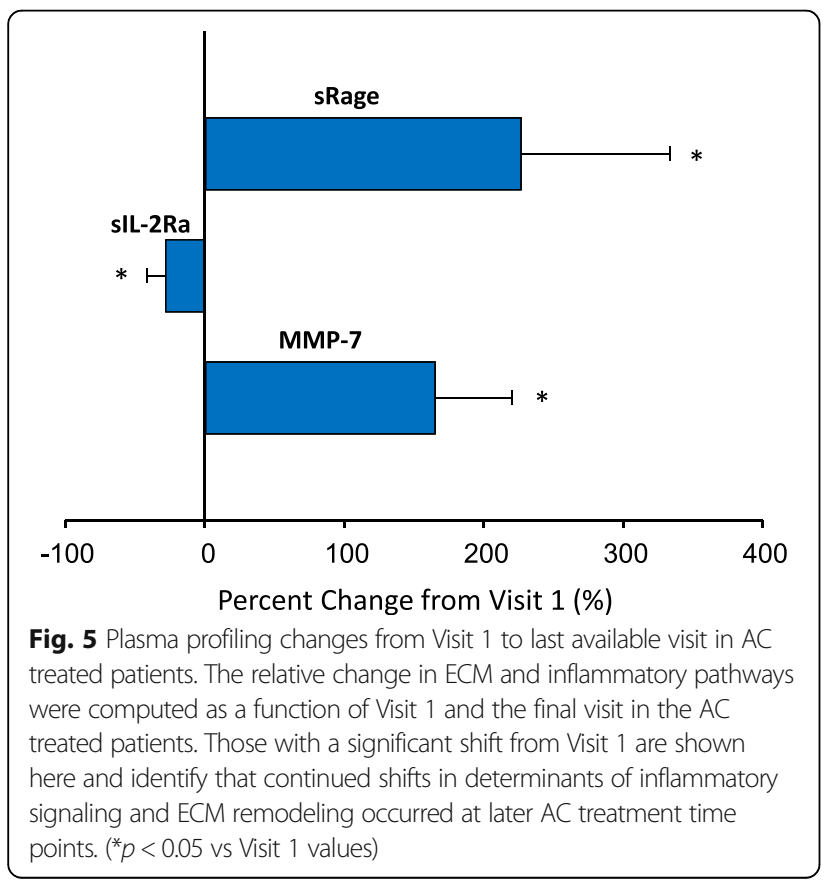

IL-1 and IL-2 receptors early in the course of AC therapy. IL-2, a human recombinant product, effective in the treatment of a variety of malignancies including neuroblastoma, has been associated with important treatmentrelated clinical toxic effects [53]. IL-2 toxicity can manifest in multiple organ systems, most significantly the heart, lungs, kidneys, and central nervous system [54]. Larger studies may help us understand how AC modulates cytokine production in relation to cardiotoxicity.

Additionally, we observed increased levels of soluble glycoprotein (sgp) 130, a common signal-transducing receptor of the IL-6 family known to be associated with mortality in congestive heart failure patients [49]. The early down-regulation of VEGF and receptor for advanced glycation end products (sRage) found in our study suggests involvement of cell growth/viability pathways responsible for vascular remodeling and myocardial angiogenesis $[55,56]$. Taken together, this data strongly indicates a role for inflammation in AIC and reveals potentially robust set of biomarkers for monitoring pediatric AIC.

\section{Extracellular matrix biomarker profiles}

Matrix metalloproteinases (MMPs) are a family of proteolytic enzymes responsible for the breakdown of the extracellular matrix [57]. Naturally occurring tissue inhibitors of MMPs (TIMPs) can partially or completely neutralize MMP function [58]. MMPs are upregulated in heart failure, and an increased myocardial MMP/TIMP ratio results in altered extracellular matrix architecture 
and adverse remodeling, leading to ventricular dilatation and dysfunction [23, 59-63]. Remodeling with loss of extracellular matrix has been demonstrated to continue for weeks after a single treatment of anthracyclines [19]. We demonstrated an early increase in MMP-2, MMP-7 and MMP-9 and detectable levels for TIMP-3 and TIMP-4 in the anthracycline group. With longer periods of AC dosing, MMP-7, a marker of macrophage proteolytic activation, increased by $165+54 \%$. Macrophages control processes of inflammation, cardiac remodeling and healing following acute coronary event, and may play a role in the pathogenesis of AIC [64].

Enhancement of MMP-2 and MMP-9, both gelatinases involved in the degradation of collagen type IV, has been shown in early AIC in h9c2 cells [38]. Strong activation of MMP-1, MMP-2, MMP-9 and a weaker induction of TIMP-1 have also been demonstrated in a porcine model [37]. Disproportionate MMP inhibitor activity may result in excessive scar formation that may convert systolic heart failure into diastolic heart failure through fibrosis and collagen deposition $[22,65]$.

\section{Mechanistic insights and future directions}

Structural changes at the time of LV assist device implantation in heart failure patients who had been exposed to $\mathrm{AC}$, have demonstrated varying degrees of adverse cardiac remodeling with moderate-to-severe myocyte hypertrophy, moderate myocytolysis, and perivascular and interstitial fibrosis with areas of replacement fibrosis [66]. Prolonged hypertrophy and fibrosis in response to pathological signals is associated with an increase in morbidity and mortality as a result of impaired left ventricular relaxation and systolic dysfunction with development of heart failure. Insights into the regulatory pathways responsible for AIC and the development of a predictive biomarker signature for early detection of myocardial dysfunction may allow early identification of patients who are most at risk for severe toxicity, as well as the evaluation of new therapies to prevent heart failure. Future innovative translational and clinical approaches, including functional imaging, biomarker and genetic profiling, will provide potential prognostic and mechanistic insights into the progression of AIC.

\section{Conclusions}

Asymptomatic pediatric patients exposed to AC chemotherapy develop myocardial strain magnitude abnormalities at low cumulative doses, with a decline in $\varepsilon$ ı preceding changes in EF. A differential biomarker signature comprised of both inflammatory and matrix domains occurs early in the treatment course. This early biomarker signature correlates with decrease in EF with increasing dose of anthracyclines. Future studies with larger number of patients will help validate our findings and may provide prognostic and mechanistic insights into the progression of AIC.

\section{Limitations}

Because of the small sample size, most of our results are descriptive, with statistically meaningful conclusions only for differences that are extremely large. Given the small sample size we were not able to not adjust $p$ values for multiple comparisons. Obtaining baseline CMR and biomarkers prior to dosing may help differentiate effect of cancer and response to chemotherapy from cardiotoxic effects and should be addressed in future studies. Although echocardiograms were performed at all visits, we chose strain calculations with HARP imaging by CMR since this technique is considered the gold standard for the measurement of regional myocardial deformation [35, 67-69]. We previously reported 2D and 3D speckle-tracking echocardiography (STE) based measurements of GLS magnitude were highly specific in identifying subjects with abnormal longitudinal strain magnitude by CMR with specificity and positive predictive value of $92 \%$ while 2D and 3D STE-derived GCS values were not predictive of decreased peak circumferential strain magnitude ( $\varepsilon c c)$ by CMR [20]. Maintaining patient compliance with the study was difficult due to the complicated treatment course in some patients, which resulted in 7 withdrawals. Newer techniques such as Strain-encoding (SENC) and DENSE (Displacement Encoding with Stimulated Echoes) MRI coupled with compressed sensing techniques will facilitate the performance of short, breath-through MRI studies for accurate estimation of parameters of regional and global myocardial function.

\section{Additional files}

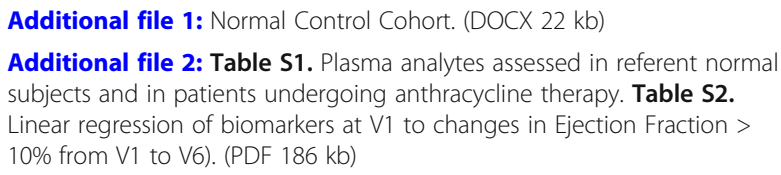

\section{Abbreviations}

AC: Anthracycline; AIC: Anthracycline induced cardiomyopathy; CMR: Cardiac magnetic resonance imaging; EF: Ejection fraction; ESFS: End systolic fiber stress; LV: Left ventricular; MMP: Metalloproteinase; ROS: Reactive oxygen species; TIMP: Inhibitors of metalloproteinase; $\varepsilon c c:$ Peak global circumferential strain magnitude; عı: Peak global longitudinal strain magnitude

\section{Acknowledgments}

The authors would like to acknowledge Rosa Rodrigues for data abstraction and entry; Kristine Hauser, RN, M.S.N., NP-C, for assisting in subject recruitment and facilitating each subject's study visit.

\section{Funding}

This study was supported by Hyundai Hope on Wheels grant (Fountain Valley, CA). 


\section{Availability of data and materials}

The datasets to support the findings of this study are available on reasonable request from the corresponding author, O.T.S.

\section{Authors' contributions}

Conception, design, and study direction: OTS, BL, KNH, CJZ, and FS. Cardiac Magnetic Resonance Imaging: OTS. Clinical oversight: BD, KNH, and EG. HARP strain analysis: $\mathrm{KNH}$, and OTS. Data analysis: JL, and ZW. Biomarker analysis: KNZ, PEP, KCM, and FS. Manuscript write-up: OTS, and JL. All authors read and approved the final manuscript.

\section{Ethics approval and consent to participate}

The patients undergoing anthracycline therapy and the referent control subjects were prospectively enrolled in this study after obtaining informed consent. All of the studies described herein were reviewed and approved by the Connecticut Children's Institutional Review Board.

\section{Consent for publication}

Not applicable.

\section{Competing interests}

The authors declare that they have no competing interests.

\section{Publisher's Note}

Springer Nature remains neutral with regard to jurisdictional claims in published maps and institutional affiliations.

\section{Author details}

${ }^{1}$ Connecticut Children's Medical Center, 282 Washington Street, Hartford, CT 06106, USA. ${ }^{2}$ University of South Carolina School of Medicine, Columbia, SC, USA. ${ }^{3}$ Nationwide Children's Hospital, Columbus, OH, USA. ${ }^{4}$ Yale University School of Medicine, New Haven, CT, USA. ${ }^{5}$ Jackson Laboratories, Bar Harbor, ME, USA. 'University of Nebraska, Omaha, NE, USA. ${ }^{7}$ Pat and Jim Calhoun Cardiology Center, University of Connecticut Health Center, Farmington, CT, USA.

Received: 15 January 2018 Accepted: 14 March 2018 Published online: 01 May 2018

\section{References}

1. Ferrans VJ, Clark JR, Zhang J, Yu ZX, Herman EH. Pathogenesis and prevention of doxorubicin cardiomyopathy. Tsitologiia. 1997;39(10):928-37.

2. Lipshultz SE, Colan SD, Gelber RD, Perez-Atayde AR, Sallan SE, Sanders SP. Late cardiac effects of doxorubicin therapy for acute lymphoblastic leukemia in childhood. NEnglJMed. 1991;324(12):808-15.

3. Toro-Salazar OH, Gillan E, Ferranti J, Orsey A, Rubin K, Upadhyay S, Mazur W Hor KN. Effect of myocardial dysfunction in cardiac morbidity and all cause mortality in childhood cancer subjects treated with anthracycline therapy. Cardio Oncol. 2015;1(1):1-9.

4. Tukenova M, Guibout C, Oberlin O, Doyon F, Mousannif A, Haddy N, Guerin S, Pacquement $\mathrm{H}$, Aouba A, Hawkins M, et al. Role of cancer treatment in long-term overall and cardiovascular mortality after childhood cancer. JClinOncol. 2010;28(8):1308-15.

5. Alvarez JA, Scully RE, Miller TL, Armstrong FD, Constine LS, Friedman DL, Lipshultz SE. Long-term effects of treatments for childhood cancers. CurrOpinPediatr. 2007;19(1):23-31.

6. Franco VI, Henkel JM, Miller TL, Lipshultz SE. Cardiovascular effects in childhood cancer survivors treated with anthracyclines. CardiolResPract. 2011;2011:134679.

7. Krischer JP, Epstein S, Cuthbertson DD, Goorin AM, Epstein ML, Lipshultz SE. Clinical cardiotoxicity following anthracycline treatment for childhood cancer: the pediatric oncology group experience. JClinOncol. 1997;15(4): 1544-52.

8. Gianni L, Herman EH, Lipshultz SE, Minotti G, Sarvazyan N, Sawyer DB. Anthracycline cardiotoxicity: from bench to bedside. JClinOncol. 2008;26(22): 3777-84.

9. Myers CE, McGuire WP, Liss RH, Ifrim I, Grotzinger K, Young RC. Adriamycin: the role of lipid peroxidation in cardiac toxicity and tumor response. Science. 1977;197(4299):165-7.

10. Swift L, McHowat J, Sarvazyan N. Anthracycline-induced phospholipase A2 inhibition. Cardiovasc Toxicol. 2007;7(2):86-91.
11. Kang YJ. Antioxidant defense against anthracycline cardiotoxicity by metallothionein. Cardiovasc Toxicol. 2007;7(2):95-100.

12. Mordente A, Meucci E, Martorana GE, Giardina B, Minotti G. Human heart cytosolic reductases and anthracycline cardiotoxicity. IUBMBLife. 2001;52(12):83-8.

13. De AA, Piegari E, Cappetta D, Marino L, Filippelli A, Berrino L, FerreiraMartins J, Zheng H, Hosoda T, Rota M, et al. Anthracycline cardiomyopathy is mediated by depletion of the cardiac stem cell pool and is rescued by restoration of progenitor cell function. Circulation. 2010;121(2):276-92.

14. Simunek T, Sterba M, Popelova O, Adamcova M, Hrdina R, Gersl V. Anthracycline-induced cardiotoxicity: overview of studies examining the roles of oxidative stress and free cellular iron. Pharmacol Reports. 2009;61(1): 154-71.

15. Deavall DG, Martin EA, Horner JM, Roberts R. Drug-induced oxidative stress and toxicity. J Toxicol. 2012;2012:645460.

16. Semsei AF, Erdelyi DJ, Ungvari I, Csagoly E, Hegyi MZ, Kiszel PS, LautnerCsorba O, Szabolcs J, Masat P, Fekete G, et al. ABCC1 polymorphisms in anthracycline-induced cardiotoxicity in childhood acute lymphoblastic leukaemia. Cell Biol Int. 2012;36(1):79-86.

17. Kong $P$, Christia $P$, Frangogiannis NG. The pathogenesis of cardiac fibrosis. Cellular Molecul Life Sci. 2014;71(4):549-74.

18. Bernaba BN, Chan JB, Lai CK, Fishbein MC. Pathology of late-onset anthracycline cardiomyopathy. Cardiovasc Pathol. 2010;19(5):308-11.

19. Caulfield JB, Bittner V. Cardiac matrix alterations induced by adriamycin. AmJPathol. 1988;133(2):298-305.

20. Toro-Salazar OH, Gillan E, O'Loughlin M, Burke GS, Ferranti J, Stainsby J, Liang B, Mazur W, Raman S, Hor K. Occult cardiotoxicity in childhood Cancer survivors exposed to anthracycline therapy. Circ Cardiovasc Imaging. 2013;6:873-80

21. Adamcova M, Potacova A, Popelova O, Sterba M, Mazurova Y, Aupperle $\mathrm{H}$, Gersl V. Cardiac remodeling and MMPs on the model of chronic daunorubicin-induced cardiomyopathy in rabbits. Physiol Res. 2010;59(5): $831-6$.

22. Lopez B, Gonzalez A, Diez J. Circulating biomarkers of collagen metabolism in cardiac diseases. Circulation. 2010;121(14):1645-54.

23. Spinale FG, Coker ML, Thomas CV, Walker JD, Mukherjee R, Hebbar L. Time-dependent changes in matrix metalloproteinase activity and expression during the progression of congestive heart failure: relation to ventricular and myocyte function. Circ Res. 1998;82(4):482-95.

24. Siwik DA, Pagano PJ, Colucci WS. Oxidative stress regulates collagen synthesis and matrix metalloproteinase activity in cardiac fibroblasts. Am J Physiol Cell Physiol. 2001;280(1):C53-60.

25. Siwik DA, Colucci WS. Regulation of matrix metalloproteinases by cytokines and reactive oxygen/nitrogen species in the myocardium. Heart Fail Rev. 2004;9(1):43-51.

26. Distefano G. Molecular pathogenetic mechanisms and new therapeutic perspectives in anthracycline-induced cardiomyopathy. ItalJPediatr. 2009; 35(1):37.

27. Lushnikova EL, Klinnikova MG, Molodykh OP, Nepomnyashchikh LM Morphological manifestations of heart remodeling in anthracycline-induced dilated cardiomyopathy. Bull Exp Biol Med. 2004;138(6):607-12.

28. Takemura G, Fujiwara H. Doxorubicin-induced cardiomyopathy from the cardiotoxic mechanisms to management. Prog Cardiovasc Dis. 2007;49(5): 330-52.

29. Thavendiranathan P, Wintersperger BJ, Flamm SD, Marwick TH. Cardiac $\mathrm{MRI}$ in the assessment of cardiac injury and toxicity from cancer chemotherapy: a systematic review. Circ Cardiovasc Imaging. 2013;6(6): 1080-91.

30. Plana JC, Galderisi M, Barac A, Ewer MS, Ky B, Scherrer-Crosbie M, Ganame J, Sebag IA, Agler DA, Badano LP, et al. Expert consensus for multimodality imaging evaluation of adult patients during and after cancer therapy: a report from the American Society of Echocardiography and the European Association of Cardiovascular Imaging. Eur Heart J Cardiovasc Imaging. 2014;15(10):1063-93.

31. Drafts BC, Twomley KM, D'Agostino R Jr, Lawrence J, Avis N, Ellis LR, Thohan V, Jordan J, Melin SA, Torti FM, et al. Low to moderate dose anthracycline-based chemotherapy is associated with early noninvasive imaging evidence of subclinical cardiovascular disease. JACC Cardiovasc Imaging. 2013;6(8):877-85.

32. Grothues F, Smith GC, Moon JC, Bellenger NG, Collins P, Klein HU, Pennell DJ. Comparison of interstudy reproducibility of cardiovascular magnetic 
resonance with two-dimensional echocardiography in normal subjects and in patients with heart failure or left ventricular hypertrophy. Am J Cardiol. 2002;90(1):29-34.

33. Billingham ME, Mason JW, Bristow MR, Daniels JR. Anthracycline cardiomyopathy monitored by morphologic changes. Cancer TreatRep. 1978;62(6):865-72.

34. Osman NF, Kerwin WS, McVeigh ER, Prince JL. Cardiac motion tracking using CINE harmonic phase (HARP) magnetic resonance imaging. Magn ResonMed. 1999;42(6):1048-60.

35. Castillo E, Lima JA, Bluemke DA. Regional myocardial function: advances in MR imaging and analysis. Radiographics. 2003;23 Spec No:S127-40.

36. Lopez B, Gonzalez A, Querejeta R, Larman M, Diez J. Alterations in the pattern of collagen deposition may contribute to the deterioration of systolic function in hypertensive patients with heart failure. JAmCollCardiol. 2006;48(1):89-96.

37. Goetzenich A, Hatam N, Zernecke A, Weber C, Czarnotta T, Autschbach R, Christiansen S. Alteration of matrix metalloproteinases in selective left ventricular adriamycin-induced cardiomyopathy in the pig. JHeart Lung Transplant. 2009;28(10):1087-93.

38. Spallarossa P, Altieri P, Garibaldi S, Ghigliotti G, Barisione C, Manca V, Fabbi P, Ballestrero A, Brunelli C, Barsotti A. Matrix metalloproteinase-2 and -9 are induced differently by doxorubicin in $\mathrm{H} 9 \mathrm{c} 2$ cells: the role of MAP kinases and NAD(P)H oxidase. CardiovascRes. 2006;69(3):736-45.

39. Mehra VC, Ramgolam VS, Bender JR. Cytokines and cardiovascular disease. J Leukoc Biol. 2005;78(4):805-18.

40. Mann DL. Inflammatory mediators and the failing heart: past, present, and the foreseeable future. Circ Res. 2002;91(11):988-98.

41. Kapadia SR. Cytokines and heart failure. Cardiol Rev. 1999;7(4):196-206

42. Fallah-Rad N, Walker JR, Wassef A, Lytwyn M, Bohonis S, Fang T, Tian G, Kirkpatrick ID, Singal PK, Krahn M, et al. The utility of cardiac biomarkers, tissue velocity and strain imaging, and cardiac magnetic resonance imaging in predicting early left ventricular dysfunction in patients with human epidermal growth factor receptor II-positive breast cancer treated with adjuvant trastuzumab therapy. J Am Coll Cardiol. 2011;57(22):2263-70.

43. Negishi K, Negishi T, Hare JL, Haluska BA, Plana JC, Marwick TH. Independent and incremental value of deformation indices for prediction of trastuzumab-induced cardiotoxicity. J Am Soc Echocardiography. 2013;26(5):493-8.

44. Olson RD, Mushlin PS. Doxorubicin cardiotoxicity: analysis of prevailing hypotheses. FASEB J. 1990;4(13):3076-86.

45. Allegra A, Alonci A, Russo S, Cannavo A, Penna G, D'Angelo A, Bellomo G, Musolino C. Cardiac involvement in patients with hematologic malignancies. J Investig Med. 2010;58(7):859-74.

46. Yokoyama T, Nakano M, Bednarczyk JL, McIntyre BW, Entman M, Mann DL. Tumor necrosis factor-alpha provokes a hypertrophic growth response in adult cardiac myocytes. Circulation. 1997;95(5):1247-52.

47. Kubota T, McTiernan CF, Frye CS, Slawson SE, Lemster BH, Koretsky AP, Demetris AJ, Feldman AM. Dilated cardiomyopathy in transgenic mice with cardiac-specific overexpression of tumor necrosis factor-alpha. Circ Res. 1997:81(4):627-35.

48. Krown KA, Page MT, Nguyen C, Zechner D, Gutierrez V, Comstock KL, Glembotski CC, Quintana PJ, Sabbadini RA. Tumor necrosis factor alphainduced apoptosis in cardiac myocytes. Involvement of the sphingolipid signaling cascade in cardiac cell death. J Clin Invest. 1996;98(12):2854-65.

49. Gullestad L, Ueland T, Vinge LE, Finsen A, Yndestad A, Aukrust P. Inflammatory cytokines in heart failure: mediators and markers. Cardiology. 2012;122(1):23-35

50. Benedict CR, Weiner DH, Johnstone DE, Bourassa MG, Ghali JK, Nicklas J, Kirlin P, Greenberg B, Quinones MA, Yusuf S. Comparative neurohormonal responses in patients with preserved and impaired left ventricular ejection fraction: results of the studies of left ventricular dysfunction (SOLVD) registry. The SOLVD investigators. J Am Coll Cardiol. 1993;22(4 Suppl A): 146A-53A.

51. Trofimov ES, Poskrebysheva AS. Study on activity of inflammatory factors in patients with chronic heart failure depending on the stage of the disease and NYHA class. Bull Exp Biol Med. 2015;158(5):614-6

52. Correia GD, Wooi Ng K, Wijeyesekera A, Gala-Peralta S, Williams R, MacCarthy-Morrogh S, Jimenez B, Inwald D, Macrae D, Frost G, et al. Metabolic profiling of children undergoing surgery for congenital heart disease. Crit Care Med. 2015;43(7):1467-76.

53. Yu AL, Gilman AL, Ozkaynak MF, London WB, Kreissman SG, Chen HX, Smith M, Anderson B, Villablanca JG, Matthay KK, et al. Anti-GD2 antibody with GM-CSF, interleukin-2, and isotretinoin for neuroblastoma. N Engl J Med. 2010;363(14):1324-34.

54. Schwartz RN, Stover L, Dutcher JP. Managing toxicities of high-dose interleukin-2. Oncology. 2002;16(11 Suppl 13):11-20.

55. Abraham D, Hofbauer R, Schafer R, Blumer R, Paulus P, Miksovsky A, Traxler $H$, Kocher A, Aharinejad S. Selective downregulation of VEGF-A(165), VEGF$R(1)$, and decreased capillary density in patients with dilative but not ischemic cardiomyopathy. Circ Res. 2000;87(8):644-7.

56. Carmeliet P. VEGF as a key mediator of angiogenesis in cancer. Oncology. 2005;69(Suppl 3):4-10.

57. Spinale FG, Coker ML, Krombach SR, Mukherjee R, Hallak H, Houck WV, Clair MJ, Kribbs SB, Johnson LL, Peterson JT, et al. Matrix metalloproteinase inhibition during the development of congestive heart failure : effects on left ventricular dimensions and function. Circ Res. 1999;85(4):364-76.

58. Li YY, Feldman AM, Sun Y, McTiernan CF. Differential expression of tissue inhibitors of metalloproteinases in the failing human heart. Circulation. 1998:98(17):1728-34

59. Spinale FG, Coker ML, Heung LJ, Bond BR, Gunasinghe HR, Etoh T, Goldberg AT, Zellner JL, Crumbley AJ. A matrix metalloproteinase induction/activation system exists in the human left ventricular myocardium and is upregulated in heart failure. Circulation. 2000;102(16):1944-9.

60. Deschamps AM, Spinale FG. Pathways of matrix metalloproteinase induction in heart failure: bioactive molecules and transcriptional regulation. CardiovascRes. 2006:69(3):666-76.

61. Ahmed SH, Clark LL, Pennington WR, Webb CS, Bonnema DD, Leonardi AH, McClure CD, Spinale FG, Zile MR. Matrix metalloproteinases/tissue inhibitors of metalloproteinases: relationship between changes in proteolytic determinants of matrix composition and structural, functional, and clinical manifestations of hypertensive heart disease. Circulation. 2006;113(17):2089-96.

62. Webb CS, Bonnema DD, Ahmed SH, Leonardi AH, McClure CD, Clark LL, Stroud RE, Corn WC, Finklea L, Zile MR, et al. Specific temporal profile of matrix metalloproteinase release occurs in patients after myocardial infarction: relation to left ventricular remodeling. Circulation. 2006;114(10): 1020-7.

63. Deardorff R, Spinale FG. Cytokines and matrix metalloproteinases as potential biomarkers in chronic heart failure. BiomarkMed. 2009;3(5):513-23.

64. Gombozhapova A, Rogovskaya Y, Shurupov V, Rebenkova M, Kzhyshkowska J, Popov SV, Karpov RS, Ryabov V. Macrophage activation and polarization in post-infarction cardiac remodeling. J Biomed Sci. 2017;24(1):13.

65. Martos R, Baugh J, Ledwidge M, O'Loughlin C, Conlon C, Patle A, Donnelly SC, McDonald K. Diastolic heart failure: evidence of increased myocardial collagen turnover linked to diastolic dysfunction. Circulation. 2007;115(7):888-95.

66. Segura AM, Radovancevic R, Demirozu ZT, Frazier OH, Buja LM Anthracycline treatment and ventricular remodeling in left ventricular assist device patients. Tex Heart Inst J. 2015:42(2):124-30.

67. Shehata ML, Cheng S, Osman NF, Bluemke DA, Lima JA. Myocardial tissue tagging with cardiovascular magnetic resonance. JCardiovascMagn Reson. 2009;11(1):55

68. Lima JA, Jeremy R, Guier W, Bouton S, Zerhouni EA, McVeigh E, Buchalter MB, Weisfeldt ML, Shapiro EP, Weiss JL. Accurate systolic wall thickening by nuclear magnetic resonance imaging with tissue tagging: correlation with sonomicrometers in normal and ischemic myocardium. J Am Coll Cardiol. 1993;21(7):1741-51.

69. Yeon SB, Reichek N, Tallant BA, Lima JA, Calhoun LP, Clark NR, Hoffman EA, Ho KK, Axel L. Validation of in vivo myocardial strain measurement by magnetic resonance tagging with sonomicrometry. J Am Coll Cardiol. 2001; 38(2):555-61. 